\title{
The evidence in a Bentall procedure with Valsalva graft: is this standard of care?
}

\author{
Ziv Beckerman ${ }^{1}$, Bradley G. Leshnower ${ }^{1}$, LaRonica McPherson ${ }^{1}$, Jose N. Binongo ${ }^{2}$, Yi Lasanajak², \\ Edward P. Chen ${ }^{1}$
}

${ }^{1}$ Division of Cardiothoracic Surgery, Department of Surgery, ${ }^{2}$ Department of Biostatistics and Bioinformatics, Rollins School of Public Health, Emory University School of Medicine, Atlanta, GA, USA

Correspondence to: Edward P. Chen, MD. Division of Cardiothoracic Surgery, Department of Surgery, Emory University School of Medicine, 5665

Peachtree Dunwoody Road, Suite 200, Atlanta, GA 30342, USA. Email: epchen@emory.edu.

\begin{abstract}
Background: Biologic valved-conduits avoids the need for anticoagulation and can exploit the excellent hemodynamic performance of stentless valves. Incorporation of the sinuses of Valsalva into the neoaortic root can improve the function and longevity of stentless valves. We report our experience in performing the Bentall procedure with a self-prefabricated composite valved-conduit and review the published experience with the Valsalva graft.
\end{abstract}

Methods: From Feb 2005 through Sep 2017, 428 patients underwent aortic root replacement utilizing a composite graft constructed from a 27-29-mm Freestyle MS valve (Medtronic) sutured into a 28-30-mm Gelweave Valsalva prosthesis (Sulzer Vascutek, Renfrewshire, Scotland). Data were retrospectively analyzed.

Results: Mean age was $58 \pm 13$ years, with a male predominance $(337,79 \%)$. Additional surgical procedures included a mitral valve repair/replacement in 10 patients (2\%), coronary artery bypass graft (CABG) in 114 patients $(27 \%)$, and aortic arch (hemi or total) replacement in 252 patients (59\%). Average cardiopulmonary bypass, cross-clamp, and circulatory arrest times were $210 \pm 57,180 \pm 44$, and $29 \pm 15 \mathrm{~min}$, respectively. Thirtyday mortality was 7\% (31 patients). Mean echocardiography follow-up was $27.2 \pm 29.0$ months (range, $1-138$ months). Pressure gradients (mean, peak) across the aortic valve on latest echocardiography were 5.59, $10.57 \mathrm{mmHg}$ respectively. Freedom from >2+ aortic insufficiency (AI) at 6 and 9 years was 96\%, and 87\% respectively. Freedom from aortic valve replacement (AVR) at 6 and 9 years was 99\%, and 95\% respectively. To date, 4 (1\%) patients required an additional aortic valve intervention secondary to structural valve degeneration.

Conclusions: Use of the Valsalva graft combined with the Freestyle valve for Bentall procedures is associated with favorable results. Clinical outcomes are excellent and in longitudinal follow-up, valve-related complications are minimal.

Keywords: Aortic root replacement; aortic valve repair; aortic root; aortic operation; aortic arch

Received: 13 February 2018; Accepted: 27 March 2018; Published: 10 May 2018.

doi: 10.21037 /jovs.2018.04.05

View this article at: http://dx.doi.org/10.21037/jovs.2018.04.05

\section{Introduction}

The Bentall procedure is considered the gold standard in the treatment of patients requiring aortic root replacement. Bentall and De Bono described their technique for aortic root replacement in 1968 (1). In 1977, Kouchoukos and colleagues (2) published their initial experience of 25 cases using coronary buttons. The Button-Bentall became one of the most significant refinements of the classic procedure. In the early 1990s, Galla et al. introduced the BioBentall which was a home-made composite graft manufactured intraoperatively using a stented bioprosthesis (3). The BioBentall provided excellent long-term survival and very low rates of thromboembolism, bleeding complications, and reoperation. Much have changed since, and in the 
current era, aortic root replacement surgery attained low early mortality, low postoperative stroke rates, and acceptable long-term survival. A few recent systematic reviews and meta-analyses demonstrated no statistical difference in short- and mid-term outcomes between biological and mechanical valve conduits for aortic root replacement; however, there remain missing data in terms of current valves long-term data, particularly with regard to reoperation rates, considering tissue conduits are not life long lasting $(4,5)$.

Gaudino et al. recently published a propensity match comparison of contemporary outcomes between valvesparing and composite valve graft replacement procedures. Their data indicated an operative mortality of $0.2 \%(0 \%$ in the valve-sparing reconstruction group). They concluded that in the current era, aortic root replacement can be performed with low perioperative risk in high-volume aortic centers. The type of operation performed does not affect early or late survival. Although the mechanical composite valved graft remains the gold standard for durability, the biologic composite valved graft and valve-sparing reconstruction are excellent options for those who cannot take or want to avoid long-term anticoagulation (6).

Several conduit options exist for performing an aortic root replacement with a biological conduit, the options vary both in relation to the implanted valve itself, whether stented or not, and in the graft-design encompassing the valve.

The native aortic root is not a stiff tube but rather a highly dynamic structure that accommodates to changes in the pressure-volume relationship in a very subtle way. During the early 1990s, Robicsek described the dynamic function of the aortic root and especially the sinuses of Valsalva (7). The sinuses of Valsalva reduce the shear stress on the cusps of the aortic valve and promote optimal coronary blood flow during diastole $(8,9)$. Another important aspect in of the facilitation of vortex formation that seems to help in smooth valve closure with less bending deformation in the longitudinal direction and reduce the stress on the coronary anastomosis (9-11). All the above factors can affect the durability and performance and longevity of the aortic bio-prosthetic valves.

Many attempts had been made by both surgeons and commercial companies to create a graft that resembles in shape and function the native aortic root (12). The Gelweave Valsalva prosthesis (Sulzer Vascutek, Renfrewshire, Scotland) is a Dacron graft with a specific design that, on implantation and pressurization, it generates three independent pseudosinuses. It is commonly used either in aortic-valve sparing procedures, or in aortic root replacements when it can be combined with a stented or stentless biological valve.

Various reports describe excellent early, and midterm outcomes with the use of the Valsalva graft for both valve sparing root procedures, and for root replacement procedures (with both biological and mechanical valves), with operative mortality rates ranging between $0-4.7 \%$, and mid-term survival of up to $100 \%$ at 36 months follow-up (13-17).

The aim of this report is to describe our institutional experience and review the up-to-date experience of the Biologic Bentall procedure using a custom made bioprosthetic conduit with the Valsalva graft and a Medtronic Freestyle Stentless Valve (Medtronic, Minneapolis, MN, USA).

\section{Methods}

\section{Patient population}

From January 2005 through September 2017, our institution's database was searched for patients undergoing aortic root replacement using a composite graft composed of the 27-29-mm Freestyle MS valve (Medtronic) sutured into a 28-30-mm Gelweave Valsalva prosthesis (Sulzer Vascutek, Renfrewshire, Scotland). We identified 428 consecutive patients. Most cases were performed by a single surgeon. Institutional review board approval was obtained for the study, and the need for individual patient consent was waived.

The indications for operation were moderate aortic insufficiency (AI) and aortic aneurysm or severe AI, with or without aortic aneurysm, or significant aortic stenosis and an aortic aneurysm.

\section{Operative technique}

All patients underwent an aortic root replacement. After median sternotomy, central aortic cannulation and right atrial venous access is obtained in patients in whom no arch reconstruction is needed. Otherwise, we routinely perform right axillary cannulation for both cardiopulmonary bypass as well as antegrade cerebral perfusion during circulatory arrest via an incision in the deltopectoral groove as previously described (18).

If the procedure was a reoperation, methods of arterial and venous cannulation varied according to the perceived risk of cardiac or aortic injury in case the procedure was a 
Table 1 Preoperative characteristics

\begin{tabular}{|c|c|}
\hline Characteristic & Summary statistic \\
\hline Age, mean $\pm S D$, range (years) & $58 \pm 13,18-87$ \\
\hline Male, $\mathrm{n}[\%]$ & 337 [79] \\
\hline Cerebrovascular disease, $\mathrm{n}[\%]$ & $45[11]$ \\
\hline COPD, n [\%] & $49[11]$ \\
\hline Diabetes, n [\%] & $68[16]$ \\
\hline Dyslipidemia, n [\%] & 264 [62] \\
\hline HTN, n [\%] & $344[80]$ \\
\hline Renal failure-dialysis, n [\%] & $3[1]$ \\
\hline Prior myocardial infarction, $\mathrm{n}$ [\%] & $62[14]$ \\
\hline Ejection fraction [\%] & $53 \pm 12$ \\
\hline Bicuspid aortic valve, $\mathrm{n}$ [\%] & $157[37]$ \\
\hline Marfan syndrome, n [\%] & $14[3]$ \\
\hline Acute type A dissection, $\mathrm{n}[\%]$ & $5[1]$ \\
\hline Endocarditis, n [\%] & $27[6]$ \\
\hline$>2+$ aortic insufficiency, n [\%] & $259[61]$ \\
\hline Aortic stenosis, $\mathrm{n}[\%]$ & $157[37]$ \\
\hline
\end{tabular}

COPD, chronic obstructive pulmonary disease.

reoperation. Chest computed tomography imaging was vital toward making this determination.

The aortic valve is inspected after aortic transection to determine non-eligibility for VSRR. The implantation procedure was done using interrupted, non pledgeted braided non-absorbable 3-0 sutures placed along the aortic annulus. The conduit is then brought down to the aortic root, and all sutures tied. Next the coronary buttons are anastomosed to their respective sinuses using a 5-0 polypropylene suture. Aortic continuity was next established.

\section{Patient follow-up}

All patients underwent intraoperative echocardiography to assess valve function. They were followed prospectively, and annual echocardiograms were obtained. Presence and degree of AI was measured and left ventricular (LV) function was recorded. AI was graded according to a semiquantitative scale: grade 0 none to trace, grade 1 mild, grade 2 moderate, grade 3 moderate to severe, and grade 4 severe. The need and timing of repeat valve interventions was also recorded.

\section{Statistical analysis}

Preoperative, intraoperative, and postoperative variables were summarized as mean \pm standard deviation [or median (interquartile range), as appropriate] for continuous variables. Count (percentage) was used for categorical variables. To compare baseline and follow-up echo data, the paired $t$-test (or the Wilcoxon signed rank test, as appropriate) was employed. Kaplan-Meier survival curves were drawn to visualize freedom from aortic valve replacement (AVR) and $\mathrm{AI}>2$. Because there was no death during follow-up, no competing risk analysis was performed. All tests of hypotheses were two-sided and conducted at 0.05 level of significance. SAS version 9.4 (Cary, NC, USA) was used to perform all statistical analyses.

\section{Outcomes}

The primary study outcome was short-term (30 days) survival after aortic root replacement. Secondary outcomes were freedom from reoperation and recurrence of AI.

\section{Results}

\section{Operative outcomes and survival}

Overall, 428 patients were identified and included in the final analyses. Preoperative and demographic data are depicted in Table 1 . Mean age was $58 \pm 13$ years, with a male predominance $(337,79 \%)$. Pre-existing comorbidities included cerebrovascular disease in 45 patients $(11 \%)$, chronic obstructive pulmonary disease (COPD) in 49 patients $(11 \%)$, diabetes mellitus in 68 patients $(16 \%)$, hypertension in 344 patients $(80 \%)$, end-stage renal failure in 3 patients (1\%), and Marfan syndrome in 14 patients (3\%).

Aortic pathologies included a bicuspid aortic valve in 157 patients $(37 \%)$, moderate/severe AI in 259 patients (61\%), moderate/severe aortic stenosis 157 patients (37\%), endocarditis in 27 patients (6\%), and acute type A aortic dissection in 5 patients (1\%). In 133 patients $(31 \%)$, the intervention was a reoperation [previous surgical procedures varied from AVR to coronary artery bypass graft (CABG) or previous root replacements]. Additional surgical procedures included a mitral valve repair/replacement in 10 patients (2\%), CABG in 114 patients (27\%), and aortic arch (hemi or total) replacement in 252 patients (59\%) (see Table 2). 
Table 2 Operative characteristics

\begin{tabular}{lc}
\hline Variable & Summary statistic \\
\hline Reoperation, $\mathrm{n}[\%]$ & $133[31]$ \\
MVR, $\mathrm{n}[\%]$ & $10[2]$ \\
CABG, $\mathrm{n}[\%]$ & $114[27]$ \\
Aortic arch replacement (hemi or total), $\mathrm{n}[\%]$ & $252[59]$ \\
CPB, mean \pm SD (minutes) & $210 \pm 57$ \\
Aortic cross clamp, mean \pm SD (minutes) & $180 \pm 44$ \\
Circulatory arrest, mean \pm SD (minutes) & $29 \pm 15$
\end{tabular}

$\mathrm{CPB}$, cardiopulmonary bypass; MVR, mitral valve replacement;

$\mathrm{CABG}$, coronary artery bypass graft.
Table 3 Postoperative outcomes

\begin{tabular}{lc}
\hline Outcome & Summary statistic \\
\hline Prolonged ventilation, n [\%] & $124[29]$ \\
LOS, mean \pm SD (days) & $9 \pm 7$ \\
IABP, n [\%] & $8[2]$ \\
Renal failure requiring hemodialysis, n [\%] & $6[1]$ \\
Temporary neurological dysfunction, $\mathrm{n}[\%]$ & $3[1]$ \\
Stroke, n [\%] & $8[2]$ \\
Operative mortality, n [\%] & $31[7]$ \\
\hline
\end{tabular}

LOS, length of stay; IABP, intra-aortic balloon pump.

Table 4 Echocardiographic data before surgery and at most recent follow-up

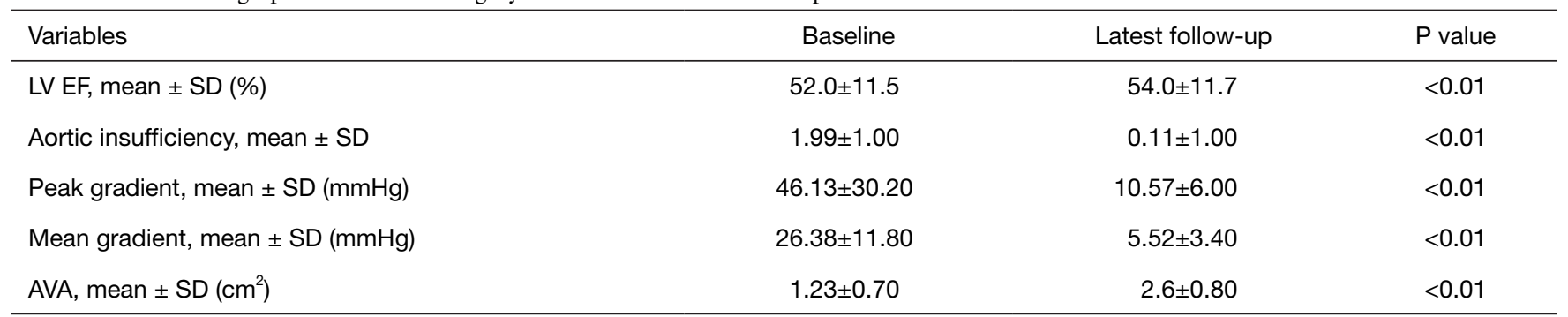

AVA, aortic valve area; LV, left ventricular; EF ejection fraction.

Average cardiopulmonary bypass, cross-clamp, and circulatory arrest times were $210 \pm 57,180 \pm 44$, and $29 \pm 15$ min, respectively.

Postoperative outcomes and 30-day mortality data are depicted in Table 3. Postoperative complications included, renal failure requiring dialysis in 6 patients $(1 \%)$, and stroke in 8 patients (2\%). Average length of stay was $9 \pm 7$ days. Eight patients (2\%) required the temporary support of intra-aortic balloon counter pulsation pump. Thirty-day mortality was $7 \%$ (31 patients), and 4\% (18 patients) among patients for whom the surgery was a reoperation.

\section{Freedom from reoperation and recurrent $A I$}

Mean echocardiography follow-up was $27.2 \pm 29.0$ months (range, 1-138 months). Mean LV ejection fraction improved significantly postoperatively $(54.0 \%$ vs. $52.0 \%, \mathrm{P}=0.01)$ (see Table 4). Average postoperative mean and peak pressure gradients across the aortic valve were 5.59 and $10.57 \mathrm{mmHg}$ respectively, in $27.2 \pm 29.0$ months (range, $1-138$ months) mean follow up.

To date, $4(1 \%)$ patients required an additional aortic valve intervention secondary to structural valve degeneration. Freedom from $>2+\mathrm{AI}$ (see Figure 1) at 6 and 9 years was $96 \%$, and $87 \%$ respectively. Freedom from AVR (see Figure 2) at 6 and 9 years was $99 \%$ and $95 \%$, respectively.

\section{Discussion}

The primary finding of this study is that aortic root replacement with a Valsalva graft-Freestyle valve conduit in this high-risk patient group, provides an excellent clinical outcome with minimal long-term valve-related complications. Overall, about $60 \%$ of the patients in this series had underwent an intervention on the aortic arch (hemi or total) replacement. In $31 \%$ of the patients, the intervention was a reoperation, increasing the surgical risk dramatically. Nevertheless, the overall 30-day mortality was only $7 \%$. The literature currently lacks data regarding the mortality and survival rates of root replacement surgery in the setting of reoperations.

Other large studies of prosthetic aortic root replacements have reported a range of short-term mortality of $0.7 \%$ to 


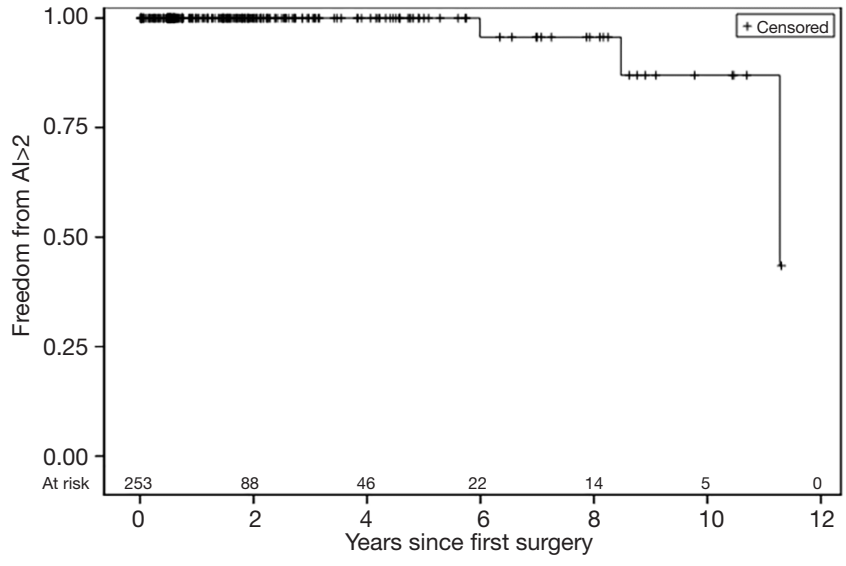

Figure 1 Freedom from $>2+$ aortic insufficiency. Follow-up median: 1.43 years, IQR: 0.53 , 2.71; minimum follow-up: 0.00 years; maximum follow-up: 11.30 years. AI, aortic insufficiency; $\mathrm{IQR}$, interquartile range.

$12 \%(19-23)$ and long-term survival of $75 \%$ at 5 years to $91 \%$ at 16 years $(23,24)$. The wide range reported in these studies is partially explained by their inclusion of higher-risk patients such as urgent or emergency operations, dissections, endocarditis, redo sternotomies, or older patients.

Review of available literature reveals several publications which attribute a potential increased valve longevity to the existence of the sinuses of Valsava. The theoretical benefits of using the Valsalva graft combined with a stentless valve includes: a larger valve orifice area, presence of sinus segments and a well-defined neo-ST junction, proper cusp opening and closing velocities, reduced aortic stress, and a potential for improved long-term valve durability. These benefits were already reported a while back by De Paulis et al. (25) who reported that the durability of aortic valvesparing procedures is negatively affected by increased leaflet stress in the absence of normally shaped sinuses of Valsalva. They described that the dynamic features of the aortic valve leaflets when implanted in the Valsalva graft to be superior to those obtained with standard straight tube conduits. Additionally, the presence of sinuses and of a well-defined sinotubular junction assures the formation of eddy currents that are of vital importance for the proper opening and closing mechanism of the aortic leaflets (26).

Tabata et al. (14) published a case series of a modified Bentall operation using the Valsalva graft combined with a stented bioprosthetic valve. They concluded that in addition to the potential benefit of the pseudo-sinuses of Valsalva on

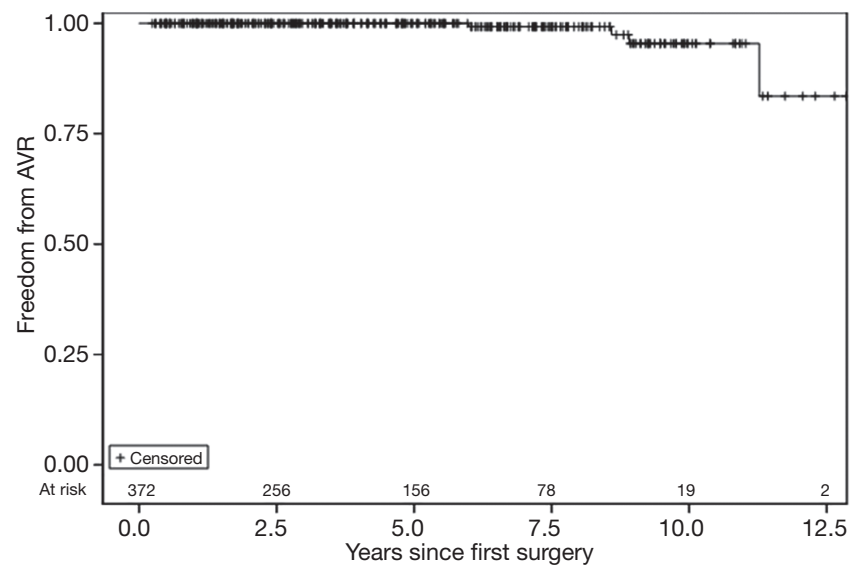

Figure 2 Freedom from aortic valve replacement. Followup median: 4.16 years, IQR: 2.06, 7.16; minimum follow-up: 0.24 years; maximum follow-up: 12.85 years. AVR, aortic valve replacement; IQR, interquartile range.

the coronary flow after Bentall operations. Theoretically, the Valsalva conduit reduces tension of coronary bottoms compared with the conventional tube graft. It also creates more space between the bioprosthetic valve struts and coronary buttons and may decrease the risk of coronary button complications. They described that passing the annular sutures through the graft collar is the major advantage of this technique.

In addition, because the valve is seated above the aortic annulus, this technique allows a surgeon to place a larger size valve than the annulus, which especially helps patients with a small aortic annulus. The effective orifice area becomes the $\mathrm{LV}$ outflow tract, not the internal diameter of the prosthetic valve (14).

\section{Limitations}

Limitations of this study include selection bias and the lack of complete follow-up. There is inherent bias in which patients are selected for undergoing a root replacement with a biological versus a mechanical valve and in which the Valsalva graft is used. Patients in this study had a mean echocardiographic follow-up of over 2 years, but this still represents a period of ongoing follow-up for these patients. In addition, echocardiographic follow-up was not $100 \%$, and cases of valve failure or recurrent aortic regurgitation (AR) could have been missed in those patients who were lost to follow-up. It is an observational study. 


\section{Conclusions}

The usage of the Valsava graft-Freestyle stentless valve combination provides all the above-mentioned potential and proven advantages of having an aortic root that resembles the normal root. Evidence suggests that the Valsalva graft has strong argument to be considered the standard of care in a Bentall procedure.

\section{Acknowledgements}

This study was supported by institutional departmental funding.

\section{Footnote}

Conflicts of Interest: The authors have no conflicts of interest to declare.

Ethical Statement: This study was approved by The Emory University (Atlanta, GA) Institutional Review Board (No. IRB00022795). The need for individual patient consent was waived.

\section{References}

1. Bentall H, De Bono A. A technique for complete replacement of the ascending aorta. Thorax 1968;23:338.

2. Kouchoukos NT, Karp RB, Lell WA. Replacement of the ascending aorta and aortic valve with a composite graft: results in 25 patients. Ann Thorac Surg 1977;24:140-8.

3. Galla JD, Lansman SL, Spielvogel D, et al. Bioprosthetic valved conduit aortic root reconstruction: the Mount Sinai experience. Ann Thorac Surg 2002;74:S1769-72; discussion S1792-9.

4. Bashir M, Harky A, Froghi S, et al. A systematic review and meta-analysis of mechanical vs biological composite aortic root replacement, early and 1-year results. Gen Thorac Cardiovasc Surg 2017. [Epub ahead of print].

5. Mookhoek A, Korteland NM, Arabkhani B, et al. Bentall procedure: a systematic review and meta-analysis. Ann Thorac Surg 2016;101:1684-9.

6. Gaudino M, Lau C, Munjal M, et al. Contemporary outcomes of surgery for aortic root aneurysms: A propensity-matched comparison of valve-sparing and composite valve graft replacement. J Thorac Cardiovasc Surg 2015;150:1120-9.e1.

7. Robicsek F. Leonardo da Vinci and the sinuses of Valsalva.
Ann Thorac Surg 1991;52:328-35.

8. de Paulis R, Tomai F, Bertoldo F, et al. Coronary flow characteristics after a Bentall procedure with or without sinuses of Valsalva. Eur J Cardiothorac Surg 2004;26:66-72.

9. Kvitting JP, Ebbers T, Wigstroem L, et al. Flow patterns in the aortic root and the aorta studied with time-resolved, 3-dimensional, phase-contrast magnetic resonance imaging: Implications for aortic valve-sparing surgery. J Thorac Cardiovasc Surg 2004;127:1602-7.

10. Beck A, Thubrikar MJ, Robicsek F. Stress analysis of the aortic valve with and without the sinuses of valsalva. J Heart Valve Dis 2001;10:1-11.

11. Katayama S, Umetani N, Sugiura S, et al. The sinus of Valsalva relieves abnormal stress on aortic valve leaflets by facilitating smooth closure. J Thorac Cardiovasc Surg 2008;136:1528-35.

12. Weltert L, De Paulis R, Scaffa R, et al. Re-creation of a sinuslike graft expansion in Bentall procedure reduces stress at the coronary button anastomoses: A finite element study. J Thorac Cardiovasc Surg 2009;137:1082-7.

13. De Paulis R, Scaffa R, Nardella S, et al. Use of the Valsalva graft and long-term follow-up. J Thorac Cardiovasc Surg 2010;140:S23-7; discussion S45-51.

14. Tabata M, Takayama H, Bowdish ME, et al. Modified Bentall operation with bioprosthetic valved conduit: Columbia University experience. Ann Thorac Surg 2009;87:1969-70.

15. Stewart AS, Takayama H, Smith CR. Modified Bentall operation with a novel biologic valved conduit. Ann Thorac Surg 2010;89:938-41.

16. Di Bartolomeo R, Pacini D, Martin-Suarez S, et al. Valsalva prosthesis in aortic valve-sparing operations. Interact Cardiovasc Thorac Surg 2006;5:294-8.

17. Pacini D, Settepani F, De Paulis R, et al. Early results of valve-sparing reimplantation procedure using the Valsalva conduit: a multicenter study. Ann Thorac Surg 2006;82:865-71; discussion 871-2.

18. Halkos ME, Kerendi F, Myung R, et al. Selective antegrade cerebral perfusion via right axillary artery cannulation reduces morbidity and mortality after proximal aortic surgery. J Thorac Cardiovasc Surg 2009;138:1081-9.

19. Etz CD, Girrbach FF, von Aspern K, et al. Longevity after aortic root replacement: is the mechanically valved conduit really the gold standard for quinquagenarians? Circulation 2013;128:S253-62.

20. Hagl C, Strauch JT, Spielvogel D, et al. Is the Bentall procedure for ascending aorta or aortic valve replacement the best approach for long-term event-free survival? Ann 
Thorac Surg 2003;76:698-703.

21. Zehr KJ, Orszulak TA, Mullany CJ, et al. Surgery for aneurysms of the aortic root: a 30-year experience. Circulation 2004;110:1364-71.

22. Varrica A, Satriano A, de Vincentiis C, et al. Bentall operation in 375 patients: long-term results and predictors of death. J Heart Valve Dis 2014;23:127-34.

23. Schachner T, Vertacnik K, Nagiller J, et al. Factors associated with mortality and long time survival in patients undergoing modified Bentall operations. J Cardiovasc Surg (Torino) 2005;46:449-55.

doi: 10.21037/jovs.2018.04.05

Cite this article as: Beckerman Z, Leshnower BG, McPherson L, Binongo JN, Lasanajak Y, Chen EP. The evidence in a Bentall procedure with Valsalva graft: is this standard of care? J Vis Surg 2018;4:98.
24. Gelsomino S, Morocutti G, Frassani R, et al. Longterm results of Bentall composite aortic root replacement for ascending aortic aneurysms and dissections. Chest 2003;124:984-8.

25. De Paulis R, De Matteis GM, Nardi P, et al. Opening and closing characteristics of the aortic valve after valvesparing procedures using a new aortic root conduit. Ann Thorac Surg 2001;72:487-94.

26. De Paulis R, Nardi P, De Matteis GM, et al. Bentall procedure with a stentless valve and a new aortic root prosthesis. Ann Thorac Surg 2001;71:1375-6. 